\title{
Characterization of inflammatory bowel disease in elderly patients: A review of epidemiology, current practices and outcomes of current management strategies
}

\author{
Peter Stepaniuk BScHons ${ }^{1}$, Charles N Bernstein MD ${ }^{1,2}$, \\ Laura E Targownik MD MSHS ${ }^{1,2}$, Harminder Singh MD MPH ${ }^{1,2,3}$
}

P Stepaniuk, CN Bernstein, LE Targownik, H Singh. Characterization of inflammatory bowel disease in elderly patients: A review of epidemiology, current practices and outcomes of current management strategies. Can J Gastroenterol Hepatol 2015;29(6):327-333.

The authors review and summarize the current literature regarding the epidemiology, clinical presentation and management of inflammatory bowel disease (IBD) in elderly patients.

Among elderly patients, the incidence of ulcerative colitis (UC) is higher than that of Crohn disease (CD). Elderly patients with a new diagnosis of UC are more likely to be male and have left-sided colitis. Elderly patients with a new diagnosis of $\mathrm{CD}$ are more likely to be female and have colonic disease. Conversely, increasing age at diagnosis has been associated with a lower likelihood of having any of a family history of IBD, perianal disease in $\mathrm{CD}$ and extraintestinal manifestations. Although response to drug therapies appears to be similar in elderly patients and younger individuals, the elderly are more likely to receive 5 -aminosalicylic acid agents, and less likely to receive immunomodulators and biologics. Corticosteroid use in the elderly is comparable with use in younger individuals. The rates of surgical intervention appear to be lower for elderly CD patients but not elderly UC patients. Elderly individuals with UC are more likely to need urgent colectomy, which is associated with an increased mortality rate. Elective surgery is associated with similar outcomes among the elderly and young patients with IBD. Therefore, the use of immunomodulators and biologics, and earlier consideration of elective surgery for medically refractory disease in elderly patients with IBD, should be emphasized and further evaluated to prevent complications of chronic corticosteroid(s) use and to prevent emergency surgery.

Key Words: Administrative data definition; Age-related differences

\author{
La caractérisation des maladies inflammatoires de \\ l'intestin chez les patients âgés : une analyse de \\ l'épidémiologie, des pratiques courantes et des \\ résultats des stratégies de prise en charge
}

Les auteurs ont analysé et résumé les publications récentes sur l'épidémiologie, la présentation clinique et la prise en charge des maladies inflammatoires de l'intestin (MII) chez les patients âgés.

Ainsi, chez les patients âgés, l'incidence de colite ulcéreuse (CU) est plus élevée que celle de la maladie de Crohn (MC). Un diagnostic de $\mathrm{CU}$ touche davantage les hommes et est davantage lié à une colite gauche, tandis qu'un diagnostic de MC touche davantage les femmes et est davantage lié à une maladie colique. En revanche, un âge plus avancé au diagnostic s'associe à une plus faible probabilité d'antécédents familiaux de MII, de MC périanale et de manifestations extra-intestinales. Même si la réponse à la pharmacothérapie semble similaire chez les personnes âgées et plus jeunes, les personnes âgées sont plus susceptibles de recevoir de l'acide 5-aminosalicylique et moins susceptibles de recevoir des immunomodulateurs et des produits biologiques. Leur utilisation de corticoïdes est toutefois comparable à celle des personnes plus jeunes. Le taux d'interventions chirurgicales semble plus faible chez les patients âgés atteints d'une $\mathrm{MC}$, mais non chez ceux atteints d'une $\mathrm{CU}$, qui risquent davantage de subir une colectomie urgente, associée à un taux de mortalité plus élevé. La chirurgie non urgente des MII donne des résultats similaires chez les personnes âgées et les patients plus jeunes. Par conséquent, il faut insister sur la possibilité d'utiliser des immunomodulateurs et des produits biologiques et d'envisager plus rapidement une chirurgie non urgente pour soigner une maladie réfractaire aux médicaments chez les personnes âgées atteintes d'une MII et l'envisager davantage pour prévenir les complications des corticoïdes chroniques et les chirurgies d'urgence.

evidence derived from analyses of population-based data sources, which are less likely to be affected by potential selection bias. We also discuss specific potential issues with the health care administrative data definition of IBD in the elderly because such data are commonly used to describe IBD epidemiology and clinical outcomes among those with IBD.

\begin{abstract}
Search strategy
PubMed was searched to August 2014 using the following key words: (Inflammatory bowel disease OR IBD OR Crohn's disease OR ulcerative colitis) AND (elderly OR age OR epidemiology OR phenotype OR medication OR surgery OR administrative). Reference lists from the articles selected were reviewed for any additional relevant articles. Abstracts were reviewed and those reporting outcomes regarding IBD in the elderly were retrieved.
\end{abstract} the epidemiology, clinical presentation, and the medical and surgical
management of both CD and UC in elderly patients. We focused on

\footnotetext{
${ }^{1}$ Internal Medicine, University of Manitoba; ${ }^{2}$ University of Manitoba IBD Clinical and Research Centre; ${ }^{3}$ Community Health Sciences, University of Manitoba, Winnipeg, Manitoba

Correspondence: Dr Harminder Singh, University of Manitoba, 805-715 McDermot Avenue, Winnipeg, Manitoba R3E 3P4.

Telephone 204-480-1311, fax 204-789-3972, e-mail Harminder.singh@med.umanitoba.ca

Received for publication February 3, 2015. Accepted March 13, 2015
} 


\section{TABLE 1 Incidence rates of ulcerative colitis (UC) and Crohn disease (CD) in elderly patients}

\begin{tabular}{lrc}
\hline & \multicolumn{2}{c}{$\begin{array}{c}\text { Incidence rate in } \\
\text { elderly* } \\
\text { per 100,000 }\end{array}$} \\
\cline { 2 - 3 } Author (reference), study period; location & UC & CD \\
\hline Lakatos et al (2), 1977-1981; Western Hungary & 1.1 & Virtually 0 \\
Shivananda et al (4), 1991-1993; Europe (men) & 10.8 & 2.9 \\
Shivananda et al (4), 1991-1993; Europe (women) & 5.3 & 2.0 \\
Bernstein et al (9), 1989-1994; Manitoba & 16.5 & 10.7 \\
Piront et al (5), 1993-1996; Liège, Belgium & 4.5 & 3.5 \\
Loftus et al (7), 1990-2000; Minnesota, USA (men) & 10.9 & 12.3 \\
Loftus et al (7), 1990-2000; Minnesota, USA (women) & 3.9 & 5.9 \\
Gower-Rousseau et al (6), 1998-2006; Northern & 3.1 & 2.6 \\
$\quad$ France & & \\
Bitton et al (11), 2001-2008; Quebec (men) & 15.9 & 13.5 \\
Bitton et al (11), 2001-2008; Quebec (women) & 13.3 & 18.9 \\
Lakatos et al (2), 2002-2008; Western Hungary & 10.8 & 3.0 \\
\hline
\end{tabular}

*Defined as $>64$ years of age in Shivananda et al (4); $>60$ years of age in Lakatos et al (2), Gower-Rousseau et al (6), Bernstein et al (9), Loftus et al (7) and Piront et al (5); and 70 to 79 years of age in Bitton et al (11)

\section{Epidemiology}

Although the incidence of IBD is greatest in the second and third decades of life, up to $15 \%$ of cases are diagnosed after 65 years of age (3). There have been several studies that have examined the epidemiology of IBD in the elderly population, which have focused on elderly persons with a new diagnosis of IBD. A brief description of some of the key studies from Europe, the United States and Canada, along with their mode of data acquisition, is included below. Incidence rates of UC and CD from the various studies are listed in Table 1.

Shivananda et al (4) reported on an inception cohort of IBD diagnosed between October 1991 and September 1993 across 20 countries in Europe comparing the incidence of both UC and CD according to age, sex and geographical location. Physicians were asked to identify all new patients seen during the study period with symptoms consistent with IBD. Patient self-help groups were also targeted with exact methods of case finding varying at each site. IBD was diagnosed on the basis of endoscopic and/or radiographic evidence supported by mucosal biopsy wherever possible. The study found that for CD, men had incidence rates of $6.0,3.2$ and 2.9 per 100,000 in the 15 to 44,45 to 64 and $>64$ age groups, respectively. Women had very similar incidence rates of $7.7,3.0$ and 2.0 per 100,000 in the different age groups, respectively. The incidence rates of UC in men were 11.2, 12.1 and 10.8 per 100,000 , and in women were $10.7,6.4$ and 5.3 per 100,000 respectively, per age groups noted above. Thus, the incidence of UC in men was stable across age groups and there was a decline with age among women. However, in this era (1991 to 1993), in Europe, UC had a greater incidence at all ages compared with CD, with the greatest differences among the elderly population.

In Belgium, Piront et al (5) assessed the epidemiology of IBD in the province of Liège between June 1, 1993 and May 31, 1996. Data were collected from a questionnaire completed by gastroenterologists in the study area. IBD diagnosis was based on the criteria of Gower-Rosseau et al (6), which includes the opinion of two expert gastroenterologists based on clinical, radiographic, endoscopic and/or histological findings. Again, a higher annual incidence rate of UC $(4.5$ per 100,000$)$ was reported among the elderly ( $\geq 60$ years of age in this study) than that of CD in the same age category $(3.5$ per 100,000$)$.

A population study using the Registre des Maladies Inflammatoires Chroniques du Tube Digestif (EPIMAD) registry from northern France with patient data from 1988 to 2008 was reported by Gower-Rousseau et al (6). The patient population consisted of all individuals $\geq 60$ years of age diagnosed with IBD during the study period based on the opinion of two expert gastroenterologists on the basis of clinical, radiographic, endoscopic and/or histological findings. This registry was established by asking gastroenterologists to report the number of IBD patients in their care. The incidence rate of CD in the elderly ( $>60$ years of age) patients was reported as 2.6 per 100,000 while the incidence rate of UC in the elderly was 3.1 per 100,000 . Although the incidence rate of $\mathrm{CD}$ was comparable with other published studies, the incidence rate of UC in elderly patients appeared to be much lower than other studies (Table 1). Of the 11,724 patients diagnosed with IBD during the study period, 1058 (9\%) were $>60$ years of age. These 1058 patients comprised $5 \%$ of all incident CD and $11 \%$ of all incident UC cases.

In Western Hungary, Lakatos et al (2) reported a population-based study examining incidence rates of IBD between 1977 and 2008 . There were 914 patients with UC and 506 with CD diagnosed between January 1, 1977 and December 31, 2008. IBD patient data were collected every year from the general hospitals, gastroenterology outpatient units and family practitioners. The study report did not describe the criteria used for IBD diagnosis. The incidence rate of UC in elderly patients (defined as $>60$ years of age in this study) was reported to have increased from 1.09 in 1977 to 1981 to 10.8 per 100,000 from 2002 to 2007 . The incidence rate of CD in the elderly also increased with CD being virtually absent in the elderly population until the 1990s, with the incidence rising to 3.04 per 100,000 from 2002 to 2007.

Loftus et al (7) reported IBD incidence rates in Olmstead County, Minnesota, USA, between 1990 and 2000. For this study, the investigators examined a central diagnostic database that included diagnoses generated from all outpatient visits, emergency room visits, hospitalizations, nursing home visits, surgical procedures, autopsy examinations and death certificates. Cases of CD were identified when they met at least two of the following criteria on two occasions two months apart: clinical history consistent with CD; endoscopic; radiological; laparotomy or histological findings of $\mathrm{CD}$. A diagnosis of $\mathrm{UC}$ required on two occasions, separated by at least six months, diffusely granular or friable colonic mucosa on endoscopy and continuous mucosal involvement on endoscopy or barium studies. The incidence rates were standardized for the 2000 United States census population. For UC, the study reported overall incidence rates of 3.9 and 10.9 per 100,000 in the $>60$ years age group for women and men, respectively. For CD, the study reported overall incidence rates of 5.9 and 12.3 per 100,000 in the $>60$ years of age group for women and men, respectively. These incidence rates appear to be slightly higher than some of the other European studies reported during the same time period.

In a population-based study using administrative health care data from the central Canadian province of Manitoba, the overall annual incidence rates for CD and UC were 14.6 and 14.3 per 100,000, respectively, between 1989 and 1994 (8). These high rates were later corroborated by a multiprovince Canadian study (9). The diagnosis of IBD was based on administrative data definition, which was validated against chart review diagnosis of IBD, based on the Lennard-Jones (10) criteria, which use a combination of clinical features, radiographic, endoscopic and pathological criteria. In the elderly population (described as $>60$ years of age in this study), incidence rates were 10.7 and 16.5 per 100,000 for CD and UC, respectively. Both of these rates were higher than other studies, possibly owing to the fact that this was one of few studies that used administrative health care data to determine incidence rates. However, the trend of UC being more common in the elderly than CD again was evident (8).

Another Canadian study from Quebec reported some of the highest incidence rates of both CD and UC. Bitton et al (11) conducted a population-based cohort study using administrative health care data. In this study, physician claims and hospitalizations in Quebec using an IBD diagnostic code from January 1996 to December 2009 were examined. Patients who received at least one hospitalization or four physician billing claims with a CD or UC diagnostic code within a two-year period were classified as having IBD; the definition was not specifically validated in Quebec. The study found overall incidence 
TABLE 2

Clinical phenotype of Crohn disease in elderly* patients

\begin{tabular}{|c|c|c|c|c|c|c|c|c|c|c|c|c|c|c|}
\hline \multirow[b]{3}{*}{ Phenotype } & \multicolumn{5}{|c|}{ Gower-Rousseau et al (6) } & \multicolumn{4}{|c|}{ Lakatos et al (2) } & \multicolumn{5}{|c|}{ Quezada et al (12) } \\
\hline & \multicolumn{5}{|c|}{ Age, years } & \multicolumn{4}{|c|}{ Age, years } & \multicolumn{5}{|c|}{ Age, years } \\
\hline & $<17$ & $17-39$ & $40-59$ & $\geq 60$ & $\mathbf{P}$ & $<19$ & $19-60$ & $>60$ & $\mathbf{P}$ & $<17$ & $17-40$ & $41-59$ & $\geq 60$ & $\mathbf{P}$ \\
\hline Male sex & 53 & 42 & 49 & 38 & $<10^{-4}$ & 62 & 47 & 52 & & 46 & 41 & 36 & 27 & 0.38 \\
\hline Perianal disease/anal fistula & 5 & 3 & 4 & 7 & 0.0006 & 32.4 & 25.1 & 9.5 & 0.051 & 45 & 32 & 13 & 22 & $<0.01$ \\
\hline Extraintestinal manifestations & 20 & 12 & 13 & 7 & $<10^{-4}$ & & & & & 27 & 28 & 27 & 18 & 0.82 \\
\hline Ileocolonic & 66 & 58 & 43 & 25 & & 45 & 30 & 0 & & 59 & 40 & 25 & 20 & \\
\hline Upper gastrointestinal & & & & & & 0 & 0.7 & 0 & & 1 & 3 & 0 & 5 & \\
\hline Nonstricturing, nonpenetrating & 72 & 66 & 69 & 78 & 0.004 & 62 & 57 & 38 & & 26 & 34 & 56 & 64 & $<0.01$ \\
\hline Stricturing & 24 & 30 & 23 & 17 & & 15 & 19 & 43 & $\ddagger$ & 31 & 31 & 33 & 14 & \\
\hline Penetrating & 4 & 4 & 8 & 5 & & 23 & 24 & 19 & & 43 & 35 & 11 & 23 & \\
\hline
\end{tabular}

Data presented as \% unless otherwise indicated. *Defined as $>60$ years of age in Lakatos et al (2), Gower-Rousseau et al (6) and Quezada et al (12); ${ }^{\dagger}$ Elderly versus pediatric: $P=0.001$; OR 5.06 (95\% Cl 1.81-14.1) and elderly versus adults: $P=0.02 ;$ OR 2.79 (95\% Cl 1.13-6.88); $\neq$ Elderly versus pediatric: $P=0.005$; OR 4.30 (95\% Cl 1.47-12.6) and elderly versus adults: $P=0.01$; OR 3.10 (95\% Cl 1.26-7.62). IBD Inflammatory bowel disease

rates of 17.4 and 10.1 per 100,000 for CD and UC, respectively, from 2001 to 2008. Incidence and prevalence rates were further standardized using the 2001 Quebec census. For CD, the study found female incidence rates of 17.5, 18.9 and 15.5 and male incidence rates of 13.7, 13.5 and 12.8 in the 60 to 69,70 to 79 and $\geq 80$ years of age groups, respectively. For UC, the study found female incidence rates of 11.4, 13.3 and 12.8 and male incidence rates of 15.0, 15.9 and 14.8 in the 60 to 69,70 to 79 and $\geq 80$ years of age groups, respectively. These rates are comparable with the above-mentioned Canadian study using administrative data.

Overall, the incidence rate of IBD in the elderly varies across Europe, the United States and Canada, with higher rates reported in Canada. The rates of UC appear to be higher than rates of CD in the elderly, and the incidence rates of both UC and CD appear to be rising in the elderly in some studies, with the UC incidence rising at a faster rate than $\mathrm{CD}$ incidence. However, of the above studies that examined the incidence of IBD in the elderly, only the North American studies used administrative health care data to identify IBD patients. The European studies relied on physicians reporting on the number of IBD cases in their respective catchment areas among other techniques and, hence, make these data not directly comparable with the North American studies. More importantly, this raises the question of whether the relatively high incidence numbers reported from Canada are truly higher than that reported from other geographical areas or if this simply reflects the method of data collection. Physician reporting can be incomplete and could be contributing to lower rates in other studies. Conversely, case misclassification in administrative records may conceivably lead to an overestimation of the incidence of IBD. Also important is that studies have used somewhat different criteria for identification and diagnosis of IBD. Most studies use a combination of clinical, radiographic, endoscopic and pathological criteria, although the specific criteria varied for each study, which could also be contributing to differences in study findings.

\section{CLINICAL PRESENTATION}

CD

An overview of the clinical phenotype of $\mathrm{CD}$ at diagnosis in the elderly can be found in Table 2. In northern France, Gower-Rousseau et al (6) examined sociodemographic and the clinical characteristics of those diagnosed with IBD after 60 years of age versus those diagnosed at younger ages. Elderly CD patients were more likely to be female and to have anal fistulas while they were less likely to have a family history of IBD or extraintestinal manifestations. A slightly higher proportion of elderly patients were found to have nonstricturing and nonpenetrating $\mathrm{CD}$ behaviour compared with younger age groups who were more likely to present with penetrating CD. Elderly patients were also more likely to have isolated colonic disease and less likely to have ileocolonic disease when compared with the younger age groups (6).

In the study from Western Hungary (2), the elderly newly diagnosed with CD were less likely to report a family history of IBD and have perianal disease, and more likely to have their disease restricted to their terminal ileum or their colon (ie, less likely to have ileocolonic disease). Compared with their younger counterparts, elderly CD patients were also more likely to present with stricturing disease compared with the pediatric and adult populations. This is in contrast with the findings of Gower-Rousseau et al (6), who found a higher proportion of elderly with perianal disease/anal fistulas and with nonstricturing, nonpenetrating behaviour.

Quezada et al (12) examined the association between age at diagnosis and CD phenotype in a cross-sectional study involving adults with CD evaluated at the University of Maryland (Baltimore, USA) between July 2004 and April 2010. In this study, the elderly (defined as those $\geq 60$ years of age at diagnosis) were less likely to have a family history of IBD and less likely to have perianal disease, similar to other studies. However, in this study, only $27 \%$ of the elderly CD population was male, which perhaps reflects that this cohort was a unique population. The elderly were found to be more likely to have colonic disease and less likely to have ileocolonic disease. Once again, the elderly were more likely to have nonstricturing and nonpenetrating disease behaviour compared with the younger age groups, similar to the French study (6).

In summary, most studies report that elderly patients diagnosed with $\mathrm{CD}$ are more likely to be female and have colonic disease compared with their younger counterparts. Furthermore, increasing age at diagnosis has been associated with a lower likelihood of family history of IBD, less perianal disease and extraintestinal manifestations.

\section{UC}

An overview of the clinical phenotype of UC at diagnosis in elderly patients is presented in Table 3 . In the French study (6), elderly UC patients were more likely to be male and less likely to have a family history of IBD or extraintestinal manifestations. Elderly patients were more likely to have left-sided colitis whereas younger patients were more likely to have extensive colitis. These findings were also found in the study from Western Hungary by Lakatos et al (2).

In a study from Allegheny County, Pennsylvania, USA, UC patients were identified using International Classification of Diseases, Ninth Revision (ICD-9) codes from the medical records at 20 hospitals in the county, which includes the metropolitan area of Pittsburgh (13). 
TABLE 3

Clinical phenotype of ulcerative colitis in elderly* patients

\begin{tabular}{|c|c|c|c|c|c|c|c|c|c|c|}
\hline \multirow[b]{3}{*}{ Phenotype } & \multicolumn{5}{|c|}{ Gower-Rousseau et al (6) } & \multicolumn{4}{|c|}{ Lakatos et al (2) } & \multirow[b]{2}{*}{ Juneja et al (13) } \\
\hline & \multicolumn{5}{|c|}{ Age, years } & \multicolumn{4}{|c|}{ Age, years } & \\
\hline & $<17$ & $17-39$ & $40-59$ & $\geq 60$ & $\mathbf{P}$ & $<19$ & $19-60$ & $>60$ & $\mathbf{P}$ & $>64$ years of age \\
\hline Male sex & 44 & 50 & 66 & 62 & $<10^{-4}$ & 47 & 53 & 52 & & \\
\hline Family history of inflammatory bowel disease & 13 & 7 & 5 & 3 & $<10^{-4}$ & 9.3 & 8.5 & 0.9 & $\dagger$ & \\
\hline Extraintestinal manifestations & 5 & 3 & 3 & 3 & $<0.05$ & & & & & \\
\hline Proctitis & 31 & 50 & 48 & 29 & $<10^{-4}$ & 23 & 26 & 21 & & 28.4 \\
\hline Left-sided & 27 & 26 & 30 & 45 & & 40 & 50 & 61 & $\ddagger$ & 25.7 \\
\hline Extensive colitis & 41 & 24 & 22 & 26 & & 37 & 24 & 18 & $\S$ & 45.9 \\
\hline
\end{tabular}

${ }^{*}$ Defined as $>64$ years of age in Juneja et al (13), and as $>60$ years of age in Lakatos et al (2) and Gower-Rousseau et al (6); ${ }^{E}$ Elderly versus pediatric: $P=0.007 ;$ OR 10.7 (95\% Cl 1.30-90.9) and elderly versus adults: $P=0.006$; OR 9.9 (95\% Cl 1.33-71.4); $¥$ Elderly versus pediatric: $P=0.005$; OR 2.38 (95\% Cl 1.30-4.36) and elderly versus adults: $P=0.025$ OR 1.61 (95\% Cl 1.06-2.44); $\$$ Pediatric versus elderly: $P=0.003$; OR 2.73 (95\% Cl 1.38-5.41) and pediatric versus adult: $P=0.01$; OR 1.89 (95\% Cl 1.15-3.11)

TABLE 4

Summary of clinical features of inflammatory bowel disease (IBD) in elderly patients

\begin{tabular}{lll}
\hline Feature & Crohn disease & Ulcerative colitis \\
\hline Sex & More commonly female & More commonly male \\
Family history of IBD & Less common & Less common \\
Perianal disease/anal fistulas & Less common & Not applicable \\
Extraintestinal manifestations & Less common & Less common \\
Localization of disease & Colonic & Left-sided colitis \\
\hline
\end{tabular}

Patient data were extracted for patients $>65$ years of age evaluated in the outpatient departments of these hospitals between January 1, 1991 and December 31, 2010. In contrast to other studies, Juneja et al (13) examined the phenotype of elderly patients with pre-existing IBD; $28.4 \%$ of patients had proctitis, $11.4 \%$ with proctosigmoiditis, $14.3 \%$ with left-sided/distal ulcerative colitis and $45.9 \%$ pancolitis. This relatively high proportion of patients with extensive colitis is in contrast to the findings of Gower-Rousseau et al (6) and Lakatos et al (2), who reported rates of extensive colitis to be $26 \%$ and $18 \%$, respectively. The relatively low proportion of patients with left-sided colitis in this study may appear to contradict the findings of Gower-Rousseau et al (6) and Lakatos et al (2), who reported rates of left-sided colitis to be $45 \%$ and $61 \%$, respectively. These findings may reflect the mode of data acquisition in these studies and, more importantly, evaluation of phenotype at disease diagnosis in the other studies versus that of prevalent IBD cases in the Pennsylvania study (13). A summary of the clinical features of IBD in elderly patients is presented in Table 4.

\section{MEDICAL TREATMENT}

The recommended treatment and their response rates for IBD in elderly patients are generally similar to that in younger individuals; however, the speed of response may be slower, which can be an important problem because of the tendency of rapid deterioration among the elderly without treatment (14). Elderly patients pose a unique challenge when determining therapy choice because patients $>60$ years of age have been not been included in most clinical trials (15). In addition, some authors have suggested that immunosuppressive therapy should be avoided in the elderly IBD population due to an increased baseline risk of infection and neoplastic complications (16). These issues reflect gaps in knowledge, which hinder the adoption of evidence-based treatment pathways in the elderly population with IBD. An overview of IBD medication usage in the elderly in clinical practice is listed in Table 5.

\section{5-aminosalicylates}

Drugs in the 5-aminosalicylate (ASA) class are commonly used for both treatment of mild-to-moderate active symptoms as well as maintenance therapy due to the safety of these drugs and their relatively benign side effect profile (17). Therefore, it may be expected that the use of 5-ASA would be favoured in the elderly. However, the prevalence of 5-ASA use among the elderly varies in different jurisdictions. In the Pennsylvania study (13), patterns of medication usage included use of a drug for more than six continuous months. They found that 5-ASA agents were the most common maintenance therapy in elderly IBD patients, with $44 \%$ of patients taking medications from this class. Although this study investigated medication usage in the entire elderly IBD population (both $\mathrm{CD}$ and $\mathrm{UC}$ ), it should be noted that there were $54 \%$ more UC patients $(n=243)$ in this study compared with CD patients $(n=150)$ and, therefore, the true utilization of 5-ASA agents in the elderly CD population cannot be discerned from this study. In a population-based French study (18), there was a combined total of 841 elderly IBD patients with recorded exposure to medications. Patients were considered to be exposed if the medication (at least one prescription) was started at diagnosis or during follow-up. The elderly IBD population had relatively high rates of 5 -ASA use, with $75 \%$ of patients exposed to this drug with similar rates in the CD and UC populations. Similar findings have also been reported from studies at tertiary care centres. For example, Bautista et al (19) performed a retrospective cohort study of patients $\geq 18$ years of age who underwent abdominal surgery for IBD between 2000 and 2010 at a single tertiary academic centre in Milwaukee, Wisconsin, USA. Patient characteristics, including exposure to medications (5-ASA, corticosteroids, immunomodulators, biologics) within two months before surgery, were included in the analysis. The patients were stratified according to age, with 42 patients in the elderly ( $>64$ years of age) age group. The patients in the elderly cohort all had pre-existing IBD with varying disease duration. In the elderly IBD cohort, 5-ASA use was higher compared with younger cohorts. Overall, only $23 \%$ of patients were exposed to this drug, significantly less than other reported studies. However, in this study, the elderly population consisted of only 42 patients (34 with CD and 8 with UC). These findings suggest that the use of 5-ASA agents is less common in the elderly CD population compared with the elderly UC population. The variation in the definition of 'exposure' in individual studies likely contributes to the difference in the prevalence of 5-ASA agents used in the different studies as does the inclusion of pre-existing IBD or elderly onset IBD. In addition, each study grouped CD and UC patients with varying proportions, making direct comparisons of medication usage in the elderly IBD population difficult. It is known that 5-ASA agents have a very limited role in $\mathrm{CD}$, whereas they are first line for mild/moderate disease in UC in the general IBD population. Overall, 5-ASA agents continue to be one of the key drugs of choice in the management of IBD in the elderly, especially those with elderly onset IBD, and its use varies across North America and Europe.

\section{Corticosteroids}

Corticosteroid use in the treatment of IBD flares is common practice because these powerful drugs can be highly effective at managing acute symptoms. However, CD patients $>50$ years of age treated with corticosteroids may be at a significantly increased risk for the development of hypertension, hypokalemia and mental status changes (20). In the 
TABLE 5

Medication usage in elderly inflammatory bowel disease patients

\begin{tabular}{|c|c|c|c|c|c|c|c|c|c|c|c|c|c|c|c|}
\hline \multirow{2}{*}{ Medication } & \multicolumn{4}{|c|}{ Lakatos et al (2) (CD) } & \multicolumn{4}{|c|}{ Lakatos et al (2) (UC) } & \multicolumn{5}{|c|}{ Bautista et al (19) } & \multirow{2}{*}{$\frac{\frac{\text { Juneja et al (13) }}{\text { Age, years }}}{>64}$} & \multirow{2}{*}{$\begin{array}{c}\text { Gower-Rousseau et al (6) } \\
\text { Age, years } \\
>60\end{array}$} \\
\hline & \multicolumn{4}{|c|}{ Age, years } & \multicolumn{4}{|c|}{ Age, years } & \multicolumn{5}{|c|}{ Age, years } & & \\
\hline Mesalamine & & & & & & & & & 13 & 6 & 10 & 23 & 0.06 & 44 & 75 \\
\hline Prednisone & 71.6 & 68.6 & 57.1 & & 57.3 & 39.8 & 17 & $\dagger$ & 34 & 37 & 31 & 23 & 0.28 & 31.6 & 31 \\
\hline Immunomodulators & 68.9 & 42.6 & 28.6 & * & 9.3 & 7.8 & 2.8 & & 62 & 69 & 55 & 45 & 0.06 & 6.9 & 16 \\
\hline Biologics & 9.5 & 9.5 & 0 & & & & & & 42 & 37 & 38 & 19 & 0.03 & 2.6 & 3.6 \\
\hline
\end{tabular}

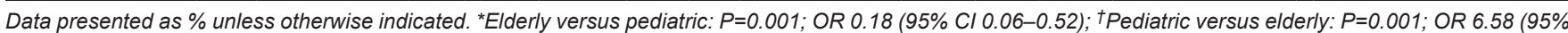
Cl 3.32-12.9), pediatric versus adult: $P=0.003$; OR 2.03 (95\% Cl 1.25-3.28), adult versus elderly: $P=0.001$; OR 3.24 (95\% Cl 1.91-5.49). CD Crohn disease; UC Ulcerative colitis

study from Western Hungary (2), patients $\geq 65$ years of age with either $\mathrm{CD}$ or UC were less likely to be exposed to corticosteroids than their younger counterparts. Only $17 \%$ of elderly UC patients received corticosteroids while $57.1 \%$ of elderly CD patients received them, although the study did not specify what constituted a medication trial. However, it should be noted that there were only 21 elderly CD patients in this study. In the study from Pensylvania (13), chronic corticosteroid use was identified in $31.6 \%$ of elderly IBD patients, which was similar to the findings in the French study (6), with $31 \%$ of elderly IBD patients exposed. Bautista et al (19) did not detect any significant difference in corticosteroid use in the elderly IBD population compared with younger cohorts, with $23 \%$ of elderly IBD patients exposed to corticosteroids. Overall, it appears that approximately one-quarter to one-third of elderly IBD patients are exposed to corticosteroids during their management, with only slightly less use compared with younger IBD patients. This appears to be independent of assessment among newly diagnosed elderly IBD patients or that among those with longstanding disease.

\section{Biologics and immunomodulators}

Biologics (adalimumab and infliximab) and immunomodulators (6-mercaptopurine, azathioprine or methotrexate) are generally reserved for individuals with severe IBD refractory to traditional therapies (21). Lakatos et al (2) and Bautista et al (19) both demonstrated decreased use of these drugs in the elderly IBD population compared with younger patients. Immunomodulator use varies, with $2.8 \%$ to $45 \%$ of elderly IBD patients exposed to these drugs whereas biologic use remains quite low, with exposure ranging from $0 \%$ to $19 \%$, with many studies reporting use in $<5 \%$ of elderly IBD patients $(2,6,13,19)$. Again, this appears to be independent of assessment among elderly onset IBD or that among elderly patients with long-standing IBD.

A retrospective chart review cohort study that examined elderly patients ( $>60$ years of age) treated with infliximab suggested that the response rate to biological agents is similar in the elderly to that in the younger patients (22). Small sample size studies, which suggest that absolute risk of complications and side effects of medications are higher in the elderly, have likely driven the lower use of immunomodulators and biologicals in elderly patients (23). Greater attention to the risks of infections and thromboembolism may mitigate these risks. In addition, alternative treatments, such as corticosteroids and urgent surgery, are also associated with higher absolute risk for complications in the elderly $(20,24)$. Furthermore, thiopurines have the propensity to interact with a number of other drugs and, thus, with polypharmacy being a common practice in elderly patients, an updated medication list should be obtained from every patient on a thiopurine (25).

\section{SURGICAL MANAGEMENT}

The principles for surgical therapy in elderly patients with IBD do not differ from their younger counterparts and is largely reserved for patients refractory to medical management. However, the rates of surgical intervention appear to be different for elderly CD patients but not elderly UC patients.
The study from Allegheny County, Pennsylvania (13) also examined patterns of bowel surgery in individuals with IBD $>65$ years of age. Individuals with CD diagnosed at $<65$ years of age were found to be significantly more likely to undergo surgery $(63.6 \%)$ than those diagnosed at $\geq 65$ years of age $(20.9 \%)$. This was attributed to elderly patients being diagnosed with $\mathrm{CD}$ earlier in life having had greater small bowel involvement compared with new-onset CD in the elderly population. Rates of surgical intervention in the elderly and younger UC populations were similar $(39.5 \%$ versus $50.9 \%$ in the younger cohort [P not significant]).

In the study from Northern France (18) ( 841 IBD patients $>60$ years of age at diagnosis from 1988 to 2006, including 367 CD and 472 UC), the cumulative probability of first intestinal resection in elderly $\mathrm{CD}$ patients was $18 \%$ (95\% CI $14 \%$ to $23 \%$ ) at one year, $27 \%$ (95\% CI $23 \%$ to $32 \%$ ) at five years and $32 \%$ (95\% CI $27 \%$ to $38 \%$ ) at 10 years from the time of diagnosis. In elderly UC, the cumulative probability of colectomy was $4 \%$ (95\% CI $2 \%$ to $6 \%$ ) at one year, $8 \%$ (95\% CI 5\% to $11 \%)$ at five years and $8 \%(95 \%$ CI $6 \%$ to $12 \%)$ at 10 years from time of diagnosis. Elderly patients with ileal or ilealcolonic CD and those with stricturing or penetrating $\mathrm{CD}$ had an increased risk for intestinal resection while the use of corticosteroids was associated with a decreased likelihood of surgery. Age, sex, extraintestinal manifestations, perianal lesions and the use of immunomodulators did not influence this risk. Of elderly UC patients, those with extensive colitis and those exposed to corticosteroids were more likely to require surgery. Age, sex, extraintestinal manifestations and use of immunomodulators did not influence this risk in UC patients.

Multiple studies that have assessed complication rates in ileoanal pouch surgery for UC have found that the incidence of anastomotic leaks, pouch-related septic complications and ileal anal pouch failure rates do not differ between younger and older patients undergoing surgery (26-28). For example, a retrospective cohort study of patients $\geq 18$ years of age who underwent abdominal surgery for IBD between 2000 and 2010 at a single tertiary academic centre in Milwaukee, Wisconsin (USA), 42 elderly IBD patients $(\geq 65)$ were matched at least $1: 1$ to patients in each of three control groups (18 to 35, 36 to 49, 50 to 64 years of age) according to sex, disease type/location and type of surgery (19). They found that the postoperative complication rate was not significantly different between the elderly and younger cohorts (38\% in 18 to $35 ; 39 \%$ in 36 to $49 ; 40 \%$ in 50 to 64 ; and $48 \%$ in $>64$ ). The only statistically significant risk factors for increased risk for complication were high Charlson comorbidity index, low preoperative hemoglobin level, total parenteral nutrition use and failed medical therapy (as an indication for surgery).

Targownik et al (29) examined colectomy in UC patients. The study's main purpose was to determine the incidence of colectomy in UC and identify risk factors associated with early and late colectomy. Patients were identified using a population-based data set that included all persons with UC in Manitoba from 1984 through 2010. Patients $<25$ years of age had higher rates of late colectomy ( $>90$ days from diagnosis) compared with patients $>65$ years of age (HR 3.30 [95\% CI 2.08 to 5.24]: $\mathrm{P}<0.0001)$. However, rates of early colectomy 
( $\leq 90$ days from diagnosis date) were higher in patients $>65$ years of age (3.1\%) compared with $1.6 \%$ of those $<65$ years of age (HR $2.00[95 \%$ CI 1.33 to 3.55 ]; $\mathrm{P}=0.0079$ ). This was postulated to be due to elderly UC patients presenting with more severe symptoms and being more prone to decompensation requiring urgent colectomy. Conversely, elective and semi-elective surgery for elderly UC patients may be less likely due to patient preference, or due to physician preference because of medical comorbidities, which would increase their risk for postoperative morbidity and mortality.

Not only are rates of early colectomy higher in elderly UC patients, but the mortality rate post-emergency colectomy also appears to be higher, as suggested by Ikeuchi et al (24): $26.7 \%$ of elderly patients ( $\geq 60$ years of age) who underwent emergency colectomy died within 30 postoperative days whereas the mortality rate was only $2.6 \%$ in patients $<60$ years of age. Pneumonia and intra-abdominal sepsis were the most common causes of death post-emergency surgery. Mortality rates following elective surgery were comparable between the two groups, with a mortality rate of $0.78 \%$ in patients $<60$ years of age and $0.88 \%$ in elderly patients.

Comorbidities play a significant role in postoperative outcomes of IBD patients, as reported by Kaplan et al (30). This study found that as the number of comorbidities in surgical patients undergoing an IBDrelated operation increased, so too did postoperative mortality. Congestive heart failure, liver disease, thromboembolic disease and renal disease were associated with a significant increase in mortality rate. Rates of postoperative death were highest for emergent surgery in the elderly population ( 65 to 80 years of age) with $\geq 2$ comorbidities $(20.6 \%)$. Elderly patients undergoing emergent surgery with $<2$ comorbidities had an $11.0 \%$ mortality rate. Mortality rates were lower in elderly patients undergoing elective IBD surgery with $\geq 2$ comorbidities (7.7\%) and with $<2$ comorbidities $(2.8 \%)$.

Thus, elderly CD patients undergo surgery less often compared with their younger counterparts, whereas elderly UC patients have surgery at rates comparable with younger patients. However, the elderly are more likely to need urgent colectomy, which is associated with an increased mortality rate, especially if the patient has underlying comorbidities. Complication rates following elective surgery are comparable in elderly and younger patients. Surgery should be performed as soon as necessary because morbidity results from prolonged ineffective medical treatment. However surgery, which can be associated with increased mortality in elderly patients (31), may also be avoided by earlier and more aggressive use of immune therapies in the elderly.

\section{ADMINISTRATIVE HEALTH CARE DATA DEFINITION OF IBD IN ELDERLY PATIENTS}

As reviewed above, referral centre studies and population-based studies using administrative data can arrive at different conclusions. One of the challenges with analyzing administrative data is the possibility of miscoding of data entry such that some individuals counted as having IBD may not truly have IBD. Because the elderly are more likely to develop ischemic colitis and may be more likely to have complicated infectious colitis there is possibly a greater risk for misclassification of IBD among the elderly, than younger populations. ICD codes - the primary diagnostic coding system used in hospital settings and for physician outpatient visits - remain of vital importance in the generation of epidemiological data. While most administrative definitions of IBD have been validated across the population of IBD, these definitions may not necessarily perform as accurately for identifying elderly individuals with IBD. Other than the fact that the elderly may be more likely to be hospitalized or seek medical care for other colitides, the elderly may have a higher prevalence of other lower gastrointestinal symptoms including rectal bleeding, fecal urgency or diarrhea, which may be misattributed to IBD. This raises the concern that accepted algorithms for identification of IBD may be less specific in the elderly, leading to a reduced positive predictive value (PPV).
Currently, only one published study (Benchimol et al [32]) has examined the accuracy of ICD diagnostic codes used in administrative health care data (hospitalization discharge abstracts and physician claims data) among elderly IBD patients. This study was undertaken in Ontario, and included hospital discharge abstract data collected from hospitals and reported to the Canadian Institute for Health Information and also billing claims for all physician services in Ontario. The most accurate algorithm in Ontario to identify individuals with IBD included five physician claims and/or hospitalizations related to IBD within four years (sensitivity $76.8 \%$; specificity 96.2\%; PPV 81.4\%; negative predictive value 95.0\%). The addition of one pharmacy claim for an IBD-related medication improved algorithm accuracy in those $>65$ years of age, improving the PPV of the algorithm without sacrificing sensitivity. The sensitivity remained constant $(59.3 \%$ ) but the PPV increased from $64.0 \%$ without a pharmacy claim to $71.1 \%$ with a pharmacy claim and $76.3 \%$ to a pharmacy claim excluding 5-ASA for elderly with IBD. However, including a pharmacy claim as part of the definition will exclude those with milder disease who do not require any medications. Importantly, this study suggests that the accuracy and PPV of administrative health care data definition of IBD is lower in the elderly than in younger individuals. This study suggested that even with the most accurate algorithm, one-quarter of elderly patients identified to have IBD in the administrative data may not have IBD. Therefore, studies using this Canadian administrative data definition to estimate incidence rates may be overestimating incidence of IBD in the elderly. The Benchimol et al (32) study results also suggest that studies on elderly IBD using administrative health care data with single occurrence of ICD codes in the databases, should be viewed with caution because of the lower accuracy (PPV of 64\%) of single ICD codes among the elderly. Our own recent study (33) suggests that while less accurate in UC, a single ICD-10 IBD code is satisfactory to identify elderly CD and UC hospitalized patients and, hence, the lower accuracy is predominantly when a single occurrence is encountered in the physician billing/outpatients datasets. More research is necessary to fully validate the administrative codes used to define $\mathrm{CD}$ and UC among the elderly in other jurisdictions.

\section{CONCLUSIONS}

IBD is an increasingly prevalent chronic immune disease affecting the elderly. The rates of $\mathrm{UC}$ appear to be higher than rates of $\mathrm{CD}$ in elderly patients, and the incidence rates of both UC and CD appear to be increasing, albeit modestly. Elderly newly diagnosed CD patients are more likely to be female and to have colonic disease and less likely to have a family history of IBD or perianal disease. Conversely, elderly patients newly diagnosed with UC are more likely to be male and have left-sided colitis and are also less likely to have a positive family history of IBD. The elderly are less likely to receive biological agents or immunomodulators or surgery. This may be secondary to concerns for risks for infection and cancer; or may reflect that the elderly do have more comorbidities and polypharmacy making the use of more medications or undergoing surgery riskier. However, because the risk for complications with corticosteroid use and that of death with urgent or emergent surgery is much higher in elderly than younger patients, optimizing treatment algorithms in the elderly with IBD is warranted. Considering the increased mortality with emergent surgery in the elderly, this is one scenario that needs to be avoided. Hence, an increase in the use of immunomodulators and biological agents and earlier elective surgery for medically refractory elderly patients with IBD should be encouraged. More research is necessary to validate the health care administrative data codes used to define $\mathrm{CD}$ and $\mathrm{UC}$ among the elderly and assess comparative incidence among the elderly in different geographical areas using standardized IBD case definition. 
DISCLOSURES: Dr Charles Bernstein is supported, in part, by the Bingham Chair in Gastroenterology. He has consulted or served on advisory boards to AbbVie Canada. Shire Canada, Takeda Canada, Forrest Canada, Cubist Pharmaceuticals, Pfizer, Theradiag and Mylan Pharmaceuticals. He has received educational grants from AbbVie Canada, Shire Canada, Takeda Canada and Janssen Canada. He has been on speakers' bureau for AbbVie Canada and Shire Canada. Laura Targownik: Speaker's Panel for Janssen Canada, Takeda Canada, Shire Canada, Pfizer Canada. Grant Support from Pfizer Canada and AbbVie Canada. Advisory Boards for Takeda Canada, AbbVie Canada, Janssen Canada. Harminder Singh: Consultant: Medial Cancer Screening Ltd. Advisory Board: Pendopharm.

\section{REFERENCES}

1. Shanahan F. The microbiota in inflammatory bowel disease: Friend, bystander, and sometime-villain. Nutr Rev 2012;70(Suppl 1):S31-7.

2. Lakatos P, David G, Pandur T. IBD in the elderly population: Results from a population-based study in Western Hungary, 1977-2008. J Crohn's Colitis 2011;5:5-13.

3. Benchimol EI, Mack DR, Nguyen GC, et al. Incidence, outcomes, and health services burden of very early onset inflammatory bowel disease. Gastroenterology 2014;147:803-13,e7.

4. Shivananda S, Lennard-Jones J, Logan R, et al. Incidence of inflammatory bowel disease across Europe: Is there a difference between north and south? Results of the European Collaborative Study on Inflammatory Bowel Disease (EC-IBD). Gut 1996;39:690-7.

5. Piront P, Louis E, Latour P, Plomteux O, Belaiche J. Epidemiology of inflammatory bowel disease in the elderly in the province of Liége. Gastroentérologie Clin Biol 2008;25:157-61.

6. Gower-Rousseau C, Vasseur F, Fumery M, et al. Epidemiology of inflammatory bowel diseases: New insights from a French population-based registry (EPIMAD). Dig Liver Dis 2013;45:89-94.

7. Loftus CG, Loftus E V, Harmsen WS, et al. Update on the incidence and prevalence of Crohn's disease and ulcerative colitis in Olmsted County, Minnesota, 1940-2000. Inflamm Bowel Dis 2007;13:254-61.

8. Bernstein C. Epidemiology of Crohn's disease and ulcerative colitis in a central Canadian province: A population-based study. Am J Epidemiol 1999;149:916-24.

9. Bernstein CN, Wajda A, Svenson LW, et al. The epidemiology of inflammatory bowel disease in Canada: A population-based study. Am J Gastroenterol 2006;101:1559-68.

10. Lennard-Jones JE. Classification of inflammatory bowel disease. Scand J Gastroenterol 1989;24:2-6.

11. Bitton A, Vutcovici M, Patenaude V, Sewitch M, Suissa S, Brassard P. Epidemiology of inflammatory bowel disease in Québec: Recent trends. Inflamm Bowel Dis 2014;20:1770-6.

12. Quezada SM, Steinberger EK, Cross RK. Association of age at diagnosis and Crohn's disease phenotype. Age Ageing 2013;42:102-6.

13. Juneja M, Baidoo L, Schwartz MB, et al. Geriatric inflammatory bowel disease: Phenotypic presentation, treatment patterns, nutritional status, outcomes, and comorbidity. Dig Dis Sci 2012;57:2408-15.

14. Vavricka S, Rogler G. Treatment of severe ulcerative colitis: Differences in elderly patients? Dig Dis 2009;27:315-21.

15. Travis S. Is IBD different in the elderly? Inflamm Bowel Dis 2008;14:S12-S13.
16. Stallmach A, Hagel S, Gharbi A, et al. Medical and surgical therapy of inflammatory bowel disease in the elderly - prospects and complications. J Crohns Colitis 2011;5:177-88.

17. Schoepfer A, Bortolotti M, Pittet V, et al. The gap between scientific evidence and clinical practice: 5 -aminosalicylates are frequently used for the treatment of Crohn's disease. Aliment Pharmacol Ther 2014;40:930-7.

18. Charpentier C, Salleron J, Savoye G, et al. Natural history of elderly-onset inflammatory bowel disease: A population-based cohort study. Gut 2014;63:423-32.

19. Bautista MC, Otterson MF, Zadvornova Y, et al. Surgical outcomes in the elderly with inflammatory bowel disease are similar to those in the younger population. Dig Dis Sci 2013;58:2955-62.

20. Akerkar GA, Peppercorn MA, Hamel MB, Parker RA. Corticosteroid-associated complications in elderly Crohn's disease patients. Am J Gastroenterol 1997;92:461-4.

21. Picco MF, Cangemi JR. Inflammatory bowel disease in the elderly. Gastroenterol Clin N Am 2009;38:447-62.

22. Moleski SM, Lindenmeyer CC, Kozuch PL. The use of infliximab in older inflammatory bowel disease patients. Gastroenterology 2011;142:S-361.

23. Ljung T. Infliximab in inflammatory bowel disease: Clinical outcome in a population based cohort from Stockholm county. Gut 2004;53:849-53

24. Ikeuchi H, Uchino M, Matsuoka H, et al. Prognosis following emergency surgery for ulcerative colitis in elderly patients. Surg Today 2014;44:39-43.

25. Ha CY. Medical management of inflammatory bowel disease in the elderly: Balancing safety and efficacy. Clin Geriatr Med 2014;30:67-78

26. Delaney C, Fazio VW, Remzi F, et al. Prospective, age-related analysis of surgical results, functional outcome, and quality of life after ileal-anal anastomosis. Ann Surg 2003;238:221-8.

27. Delaney C, Dadvand B, Remzi F, Church J, Fazio V. Functional outcome, quality of life, and complications after ileal pouch-anal anastomosis in selected septuagenarians. Dis Colon Rectum 2002;45:890-4.

28. Fazio VW, Tekkis PP, Remzi F, Lavery IC. Quantification of risk for pouch failure after ileal pouch anal anastomosis surgery. Ann Surg 2003;238:605-17.

29. Targownik LE, Singh H, Nugent Z, Bernstein CN. The epidemiology of colectomy in ulcerative colitis: Results from a population-based cohort. Am J Gastroenterol.2012;107:1228-35.

30. Kaplan G, Hubbard J. Risk of comorbidities on postoperative outcomes in patients with inflammatory bowel disease. Arch Surg 2011;146:959-64.

31. Bernstein CN, Nugent Z, Targownik LE, Singh H, Lix LM. Predictors and risks for death in a population-based study of persons with IBD in Manitoba. Gut 2014:1-9.

32. Benchimol EI, Guttmann A, Mack DR, et al. Validation of international algorithms to identify adults with inflammatory bowel disease in health administrative data from Ontario, Canada. J Clin Epidemiol 2014;67:887-96.

33. Stepaniuk P, Bernstein CN, Nugent Z, Singh H. Characterization of inflammatory bowel disease in elderly hospitalized patients in a large central Canadian Health Region. Can J Gastroenterol Hepatol 2015;29:274-8. 


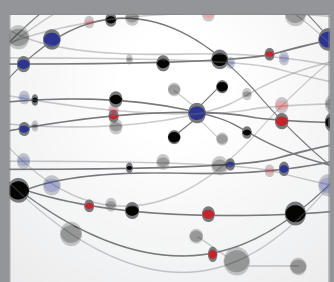

The Scientific World Journal
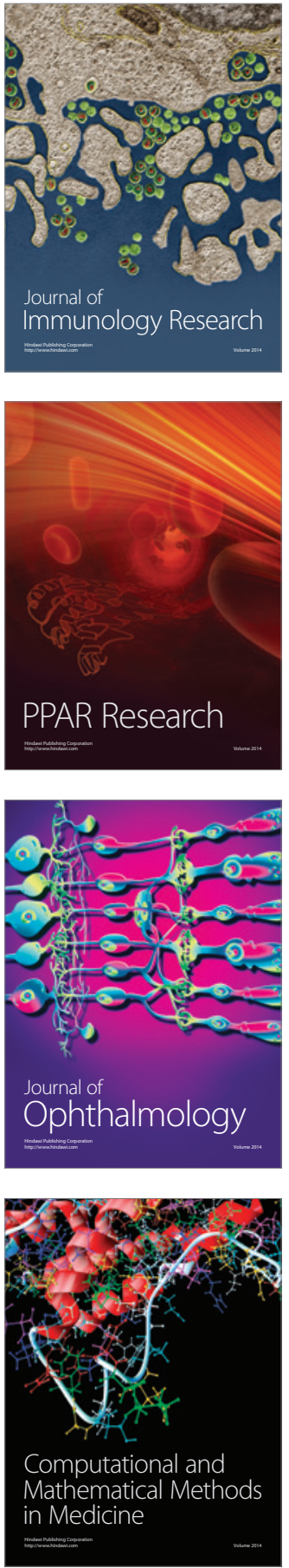

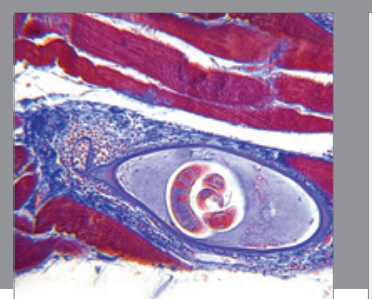

Gastroenterology Research and Practice

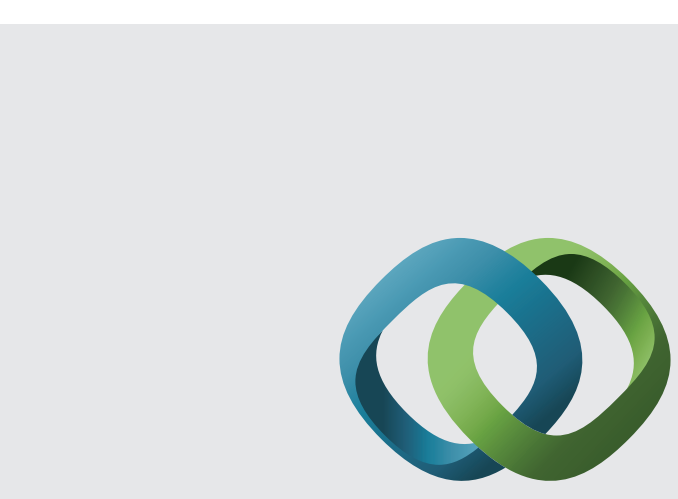

\section{Hindawi}

Submit your manuscripts at

http://www.hindawi.com
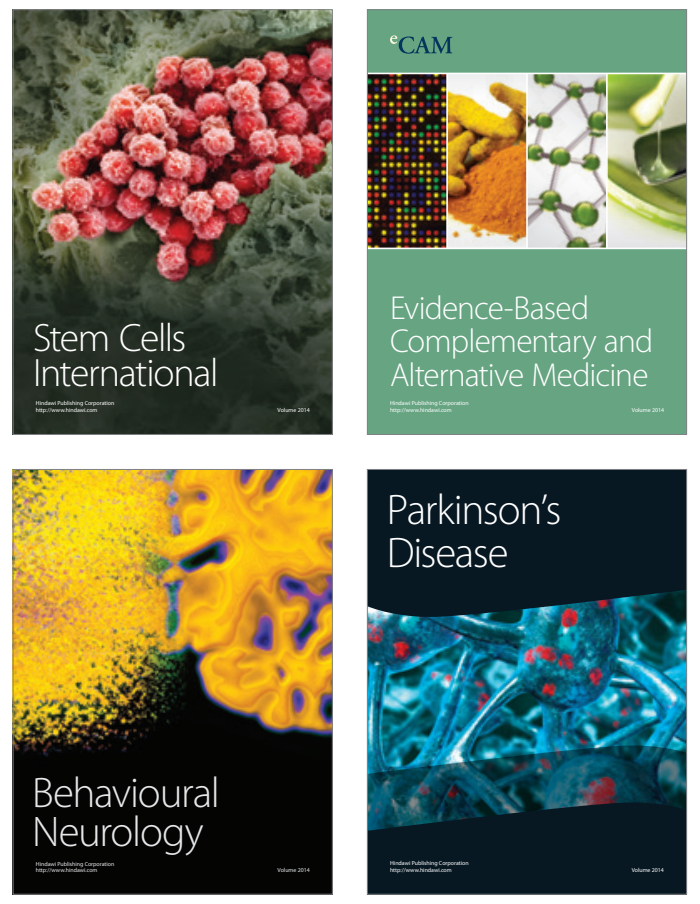
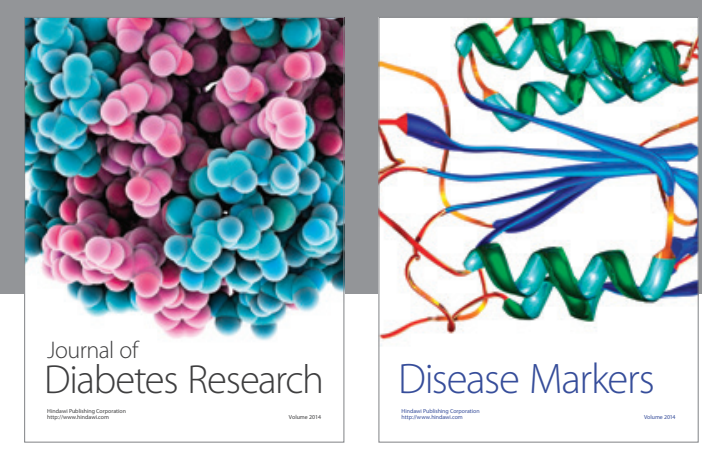

Disease Markers
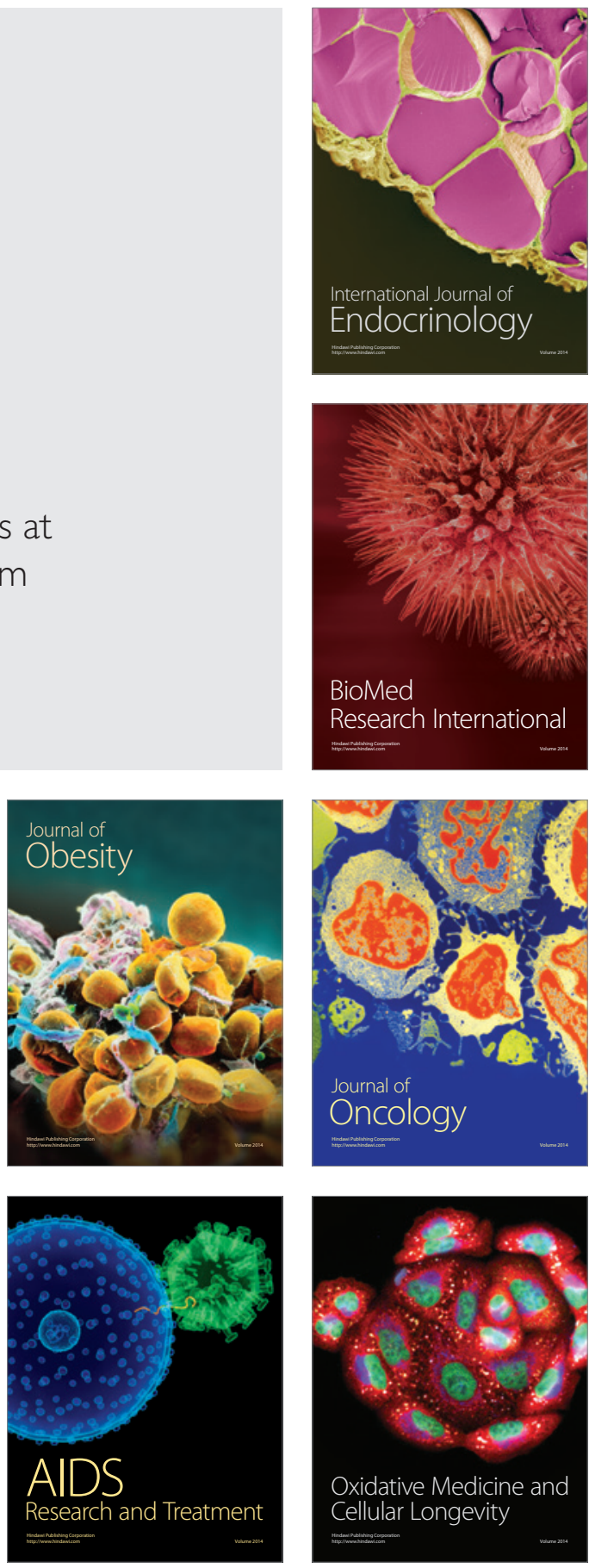